\title{
Metabolites of a Diatom, Synedra rumpens Kürz. isolated from Water in Lake Biwa. Identification of Odorous Compounds, $n$-Hexanal and $n$-Heptanal, and Analysis of Fatty Acids ${ }^{1)}$
}

\author{
Tohru Kikuchi, Tetsutaro Mimura, ${ }^{2 a)}$ Yoshihisa Moriwaki, \\ Masayoshi Ando, ${ }^{2 b)}$ and Ken-IChiro Negoro ${ }^{20}$ \\ Faculty of Pharmacentical Sciences, Kyoto University, ${ }^{2 a)}$ Water Supply Bureau, \\ Kyoto City, ${ }^{2 b}$ and Otsu Hydrobiological Station \\ of Kyoto University ${ }^{2 c)}$
}

(Received October 17, 1973)

\begin{abstract}
A diatom, Synedra rumpens Kürz., was isolated from the water in Lake Biwa which is the source of the water supplies of Kyoto City. Two odorous metabolites produced by this alga were proved to be $n$-hexanal and $n$-heptanal by means of gas chromatography (GC) and GC-mass spectrum.

Three of four fatty acids obtained from Synedra rumpens KüTz. were also identified as isovaleric, myristic, and palmitic acids by GC.
\end{abstract}

In recent years, there occurred frequently remarkable multiplications of several algae and actinomycetes in rivers and lakes accompanied with the water pollution. Metabolites of these aquatic organisms are responsible for the objectionable odors and tastes developed in public water supplies. ${ }^{3)} \quad$ One of the causative materials of these odors and tastes was already proved to be geosmin ${ }^{4)}$. produced by some of actinomycetes ${ }^{5)}$ and blue-green algae. ${ }^{6,7)}$ Recently it was suggested that 2-methylisoborneol ${ }^{8)}$ produced by actinomycetes was also a causative agent. ${ }^{7 a, 9)}$ In 1969 , at the time of occurrence of unpleasant odors and tastes in water supplies of Kyoto City, there was observed an extraordinary increase of a diatom, Synedra rumpens Kürz., in the Southern Basin of Lake Biwa which is the raw water source of Kyoto City. ${ }^{10)}$ Therefore, this alga was supposed to be one of the origins of these odors and tastes, and its metabolites were examined. In this paper, we will report the isolation and identification of its odorous metabolites and fatty acids.

1) A part of this work was reported in the preliminary communication: T. Kikuchi, T. Mimura, Y. Moriwaki, M. Ando, and K. Negoro, Yakugaku Zasshi, 92, 1567 (1972).

2) Location: a) Yoshida-shimoadachi-cho, Sakyo-ku, Kyoto; b) Awataguchi-kacho-cho, Higashiyama-ku, Kyoto; c) Shimosakamoto-cho, Otsu.

3) Report of the AWWA Committee on Tastes and Odors, J. Amer. Water Works Assoc., 62, 59 (1970).

4) N.N. Gerber, Tetrahedron Letters, 1968, 2971.

5) N.N. Gerber and H.A. Lechevalier, Appl. Microbiol., 13, 935 (1965); N.N. Gerber, Biotechnol. and Bioeng., 9, 321 (1967); A.A. Rosen, R.S. Safferman, C.I. Mashni, and A.H. Romano, Appl. Microbiol., 16, 178 (1968); T. Kikuchi, T. Mimura, Y. Moriwaki, K. Negoro, S. Nakazawa, and H. Ono, Yakugaku Zasshi, 91, 1255 (1971); idem, ibid., 92, 652 (1972).

6) R.S. Safferman, A.A. Rosen, C.I. Mashni, and M.E. Morris, Environ. Sci. Technol., 1, 429 (1967); L.L. Medsker, D. Jenkins, and J.F. Thomas, ibid., 2, 461 (1968); T. Kikuchi, T. Mimura, K. Harimaya, H. Yano, T. Arimoto, Y. Masada, and T. Inoue, Chem. Pharm. Bull. (Tokyo), 21, 2342 (1973).

7) a) A.A. Rosen, C.I. Mashni, and R.S. Safferman, Water Treatment and Examination, 19, 106 (1970); b) T. Kikuchi, T. Mimura, and Y. Moriwaki, Yakugaku Zasshi, 92, $1441(1972)$; c) T. Kikuchi, T. Mimura, Y: Masada, and T. Inoue, Chem. Pharm. Bull. (Tokyo), 21, 1847 (1973).

8) L.L. Medsker, D. Jenkins, and J.F. Thomas, Envivon. Sci. Technol., 3, 476 (1969); N.N. Gerber, J. Antibiotics (Tokyo), 22, 508 (1969).

9) T. Kikuchi, T. Mimura, Y. Moriwaki, K. Negoro, S. Nakazawa, and H. Ono, Yakugaku Zasshi, 93, 658 (1973); T. Kikuchi, T. Mimura, Y. Itoh, Y. Moriwaki, K. Negoro, Y. Masada, and T. Inoue, Chem. Pharm. Bull. (Tokyo), 21, 2339 (1973).

10) K. Negoro, Mizu (Water), 14, No. 1, 31 (1972); idem, ibid., 14, No. 5, 59 (1972). 
Pure culture of Synedra rumpens KüTz. with Detmer medium gave the algal cells (wet weight $c a .10 \mathrm{~g}$ ) with a fishy odor. These cells were extracted with methylene chloride and then with methanol, and each extract was treated as shown in Chart 1. A sample (fract. I) obtained from about a half portion of the methylene chloride extract by silica gel column chromatography showed a fishy odor, which might be ascribed to some aldehydic substances. ${ }^{11)}$ Gas chromatographic examination of this fraction (fract. I) using three kinds of columns (10\% PEG 20 M, 10\% SE-30, and 15\% Reoplex 400) revealed the presence of two compounds having the same retention time as $n$-hexanal and $n$-heptanal, respectively. Fig. 1 shows the gas chromatogram taken on a $15 \%$ Reoplex 400 column, where the peaks A and B correspond to $n$-hexanal and $n$-heptanal, respectively.

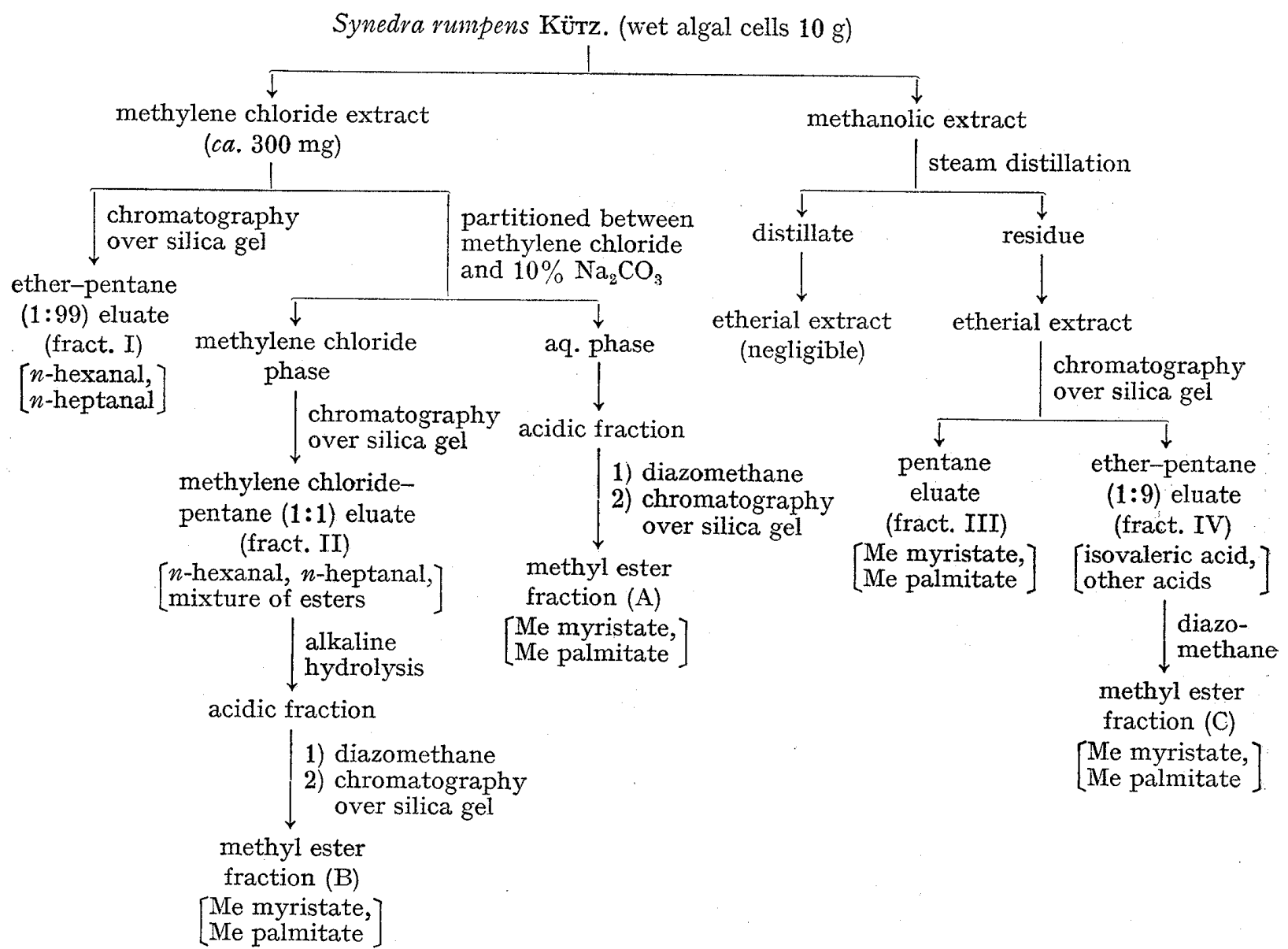

Chart 1. Scheme for the Separation of Odorous Metabolites and Fatty Acids from Synedra rumpens KüTz.

In order to confirm this finding, fraction I was then examined by mass spectrometry combined with gas chromatography (GC-MS) using a Golay column HB 2000. The mass spectrum of the peak $A$ reveals the molecular ion peak at $m / e 100$, corresponding to a molecular formula $\mathrm{C}_{6} \mathrm{H}_{12} \mathrm{O}$. Furthermore, the mass spectrum of the peak $\mathrm{A}$ is superimposable upon that of authentic $n$-hexanal measured under the same condition (Fig. 2). On the other hand, the mass spectrum of the peak $B$ shows the molecular ion peak at m/e $114\left(\mathrm{C}_{7} \mathrm{H}_{14} \mathrm{O}\right)$, and its spectral pattern is identical with that of authentic $n$-heptanal as shown in Fig. $3 .{ }^{12}$ )

11) R.P. Collins and K. Kalnins, Lloydia, 28, 48 (1965).

12) In a previous experiment reported in the preliminary communication, ${ }^{1}$ ) $n$-hexanal was detected from the oily substance obtained by steam distillation of the methanolic extract, but in this experiment neither $n$-hexanal nor $n$-heptanal was detected from the corresponding fraction. 
On the other hand, another sample (fract. II) obtained from the rest of the methylene chloride extract was found to be composed mainly of ester-like substances by the IR spectrum and the hydrolysis experiment. Nevertheless, the existence of $n$-hexanal and $n$-heptanal in this fraction was ascertained by gas chromatography using a 10\% PEG $20 \mathrm{M}$ column.

Next we examined the fatty acids of this alga. There are many reports on the fatty acids and lipids of planktonic algae. For instance, Kates, et al. ${ }^{13)}$ examined the lipids of one fresh-water and five marine species of diatoms and reported that the major fatty acid constituents are palmitoleic, palmitic, eicosapentaenoic, and eicosatetraenoic acids.

The gas chromatograms taken on a $15 \%$ PEGS column of methyl ester fractions, (A) and (B), obtained from the methylene chloride extract (see Chart 1 ) showed three peaks as illustrated in Fig. 4. Of these, the peaks $C$ and $D$ were proved to be methyl myristate and methyl palmitate, respectively, by the direct comparison with respective authentic samples. The remaining one (peak E) was supposed to be an unsatu-

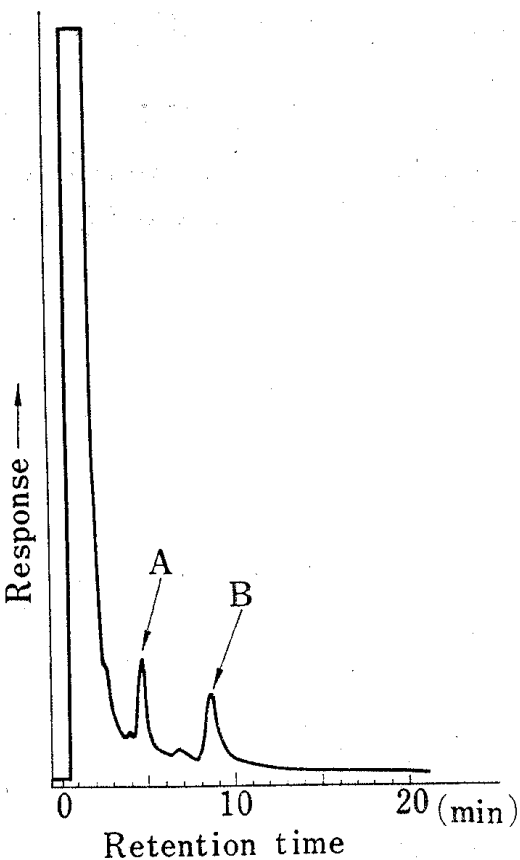

Fig. 1. Gas Chromatogram of the Odorous Metabolites (Fract. 1) of Synedva vumpens KüTz.

condition: column, $15 \%$ Reoplex 400 ; column temp., $00^{\circ}$; carrier gas, $\mathrm{N}_{2}(30 \mathrm{ml} / \mathrm{min})$
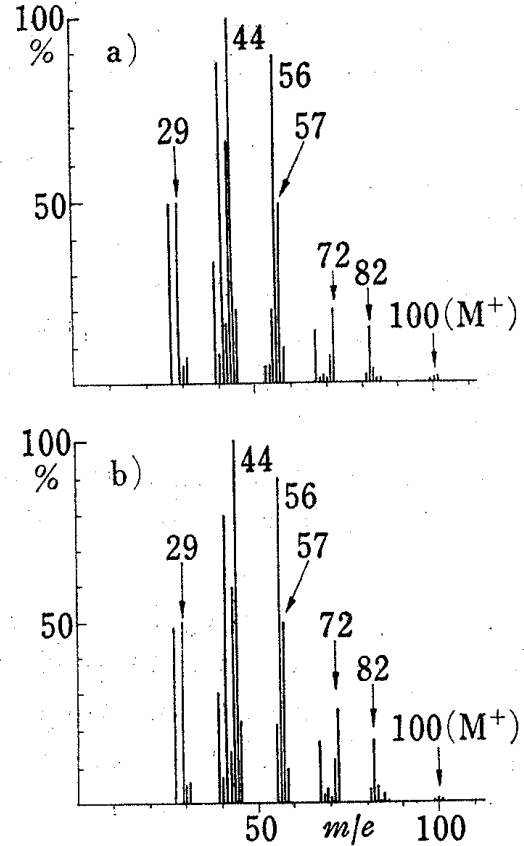

Fig. 2. a) Mass Spectrum of an Odorous Metabolite (Peak A) of Synedra rumpens KüTz.; b) Mass Spectrum of Authentic $n$-Hexanal

condition: GC column, Golay HB 2000; column temp., $30^{\circ}$; carrier gas, $\mathrm{He}\left(0.6 \mathrm{~kg} / \mathrm{cm}^{2}\right) ; \mathrm{MS}$ ionization voltage, $80 \mathrm{eV}$; accelerator voltage, $2 \mathrm{kV}$
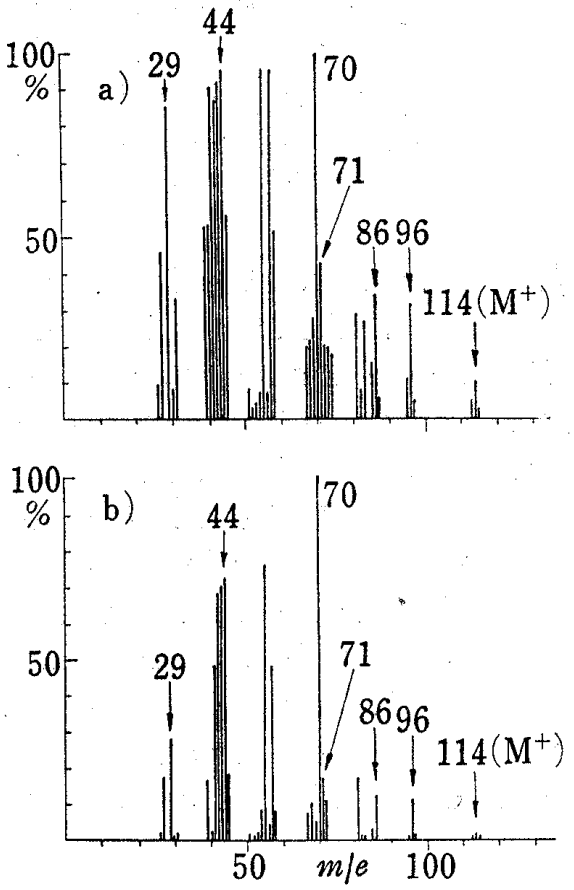

Fig. 3. a) Mass Spectrum of another Odorous Metabolite (Peak B) of Synedra rumpens KÜTZ.; b) Mass Spectrum of Authentic $n$-Heptanal

condition: the same as described in the legend to Fig. 2.

13) M. Kates and B.E. Volcani, Biochim. Biophys. Acta, 116, 264 (1966); idem, Z. Pflanzenphysiol., 60, 19 (1968). 
rated fatty acid methyl ester, but the identification of this compound could not be achieved.

Also, small quantities of methyl myristate, methyl palmitate, and the above unidentified fatty acid methyl ester were detected from the fract. III obtained from the methanolic extract (Chart 1) by gas chromatography. ${ }^{14)}$

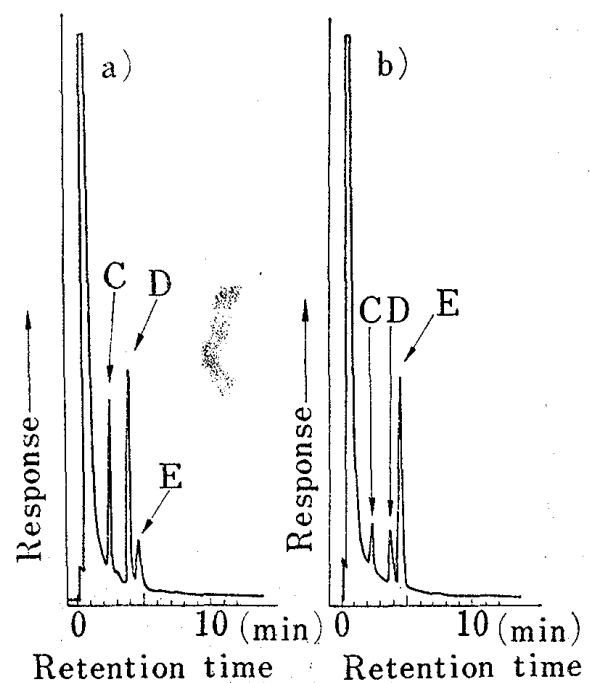

Fig. 4. a) Gas Chromatogram of Methy! Ester Fraction (A) of Synedra rumpens KüTz.; b) Gas Chromatogram of Methyl Ester Fraction (B) of Synedra rumpens KüTz.

condition: column, $15 \%$ PEGS; column temp., $180^{\circ}$; carrier gas, $\mathrm{N}_{\mathrm{g}}(30 \mathrm{ml} / \mathrm{min})$

C: methyl myristate; D: methyl palmitate; E: the unidentified fatty acid methyl ester

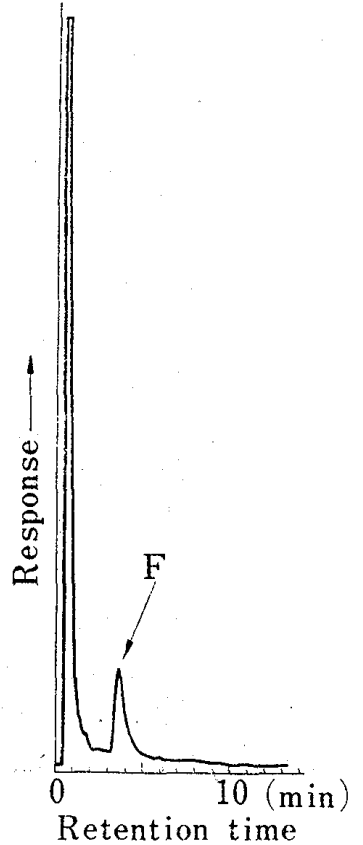

Fig. 5. Gas Chromatogram of the Fatty Acids (Fract. IV) of Synedra rumpens KüTZ.

condition: column, $15 \%$ PEGS; column temp., $150^{\circ}$; carrier gas, $\mathrm{N}_{2}(30 \mathrm{ml} / \mathrm{min})$

$\mathrm{F}$ : isovaleric acid

On the other hand, the fract. IV from the methanolic extract is composed mainly of acidic substances. As shown in Fig. 5, gas chromatographic examination of this fraction using a $15 \%$ PEGS column revealed the presence of a small amount of isovaleric acid, whose identity was confirmed by comparison with an authentic sample.

Treatment of the fract. IV with diazomethane gave an ester mixture (methyl ester fraction (C) in Chart 1), from which methyl myristate, methyl palmitate, and the unidentified methyl ester were detected by gas chromatography.

In view of the above finding, the fishy-smelling compounds produced by Synedra rumpens Küтz. were proved to be $n$-hexanal and $n$-heptanal. These compounds were reported as the odorous metabolites of a golden-brown alga, Synura petersenii EHR., ${ }^{11)}$ but our present result is the first example of detection from diatoms. Also, isovaleric acid may be responsible jointly with other odorous compounds for the unpleasant odors and tastes.

\section{Experimental}

Pure Culture of Synedra rumpens KüTz. and Extraction of the Metabolites___Synedra rumpens KüTz. was isolated from the raw water of Kyoto City water supplies which was taken from the Southern Basin of Lake Biwa through the Biwako Driving Canal No. 2. This diatom was cultured with Detmer medium (150 ml) at $20^{\circ}$ for 15 days under illumination by Plantlux $(20 \mathrm{~W}$, Toshiba) and Homolux $(20 \mathrm{~W}$, National $)$. The algal cells obtained were further cultured with Detmer medium of two-fold concentration (20 liters) for

14) We imagine that the methyl esters included in fract. III might be artifacts produced during the extraction with methanol. 
9 days and then with Detmer medium of ten-fold concentration (20 liters) for 7 days. Stirring of the culture medium was done by continuous bubbling of air. Centrifugation $(12000 \mathrm{rpm}, 30 \mathrm{~min})$ of this culture broth gave the algal cells (wet weight $c a .10 \mathrm{~g}$ ), which were extracted with methylene chloride ( 3 times) at room temperature and then with methanol ( 3 times). The methylene chloride solution was dried over anhyd. $\mathrm{MgSO}_{4}$ and carefully evaporated to afford an oily substance (ca. $300 \mathrm{mg}$ ) with a fishy odor and a characteristic "odor of the sea". On the other hand, the combined methanol solution was concentrated until almost all of methanol was removed, giving an oily substance possessing a characteristic "odor of the sea".

Separation of Odorous Metabolites and Fatty Acids from the Methylene Chloride Extracts-About a half portion of the methylene chloride extract was subjected to silica gel column chromatography $(2 \mathrm{~g}, 1 \times$ $5 \mathrm{~cm})$. After elution with pentane $(20 \mathrm{ml})$, elution with 1: 99 ether-pentane $(20 \mathrm{ml})$ afforded a small amount of oily substance showing a fishy odor (fract. I).

The rest of the methylene chloride extract was partitioned between methylene chloride and $10 \% \mathrm{Na}_{2} \mathrm{CO}_{3}$. The aqueous layer was acidified with $\mathrm{HCl}$ and extracted with methylene chloride ( 3 times), and the combined extract was washed with water, dried (anhyd. $\mathrm{MgSO}_{4}$ ), and evaporated to give an oily acidic substance $(24 \mathrm{mg})$. This was treated with etherial $\mathrm{CH}_{2} \mathrm{~N}_{2}$, and the product was purified by silica gel column chromatography $(0.25 \mathrm{~g}, 0.5 \times 1.7 \mathrm{~cm})$ to afford an ester mixture (methyl ester fraction $(\mathrm{A}))(5 \mathrm{mg}), \mathrm{IR}_{\mathrm{max}^{\mathrm{C}}}^{\mathrm{CHCl}_{8}} \mathrm{~cm}^{-1}$ : 1725 .

On the other hand, the organic layer was dried over anhyd. $\mathrm{MgSO}_{4}$ and evaporated to give an. oily neutral substance $(100 \mathrm{mg})$, which was subjected to silica gel column chromatography $(6 \mathrm{~g}, 1.4 \times 12.5 \mathrm{~cm})$. Elution with 1:1 methylene chloride-pentane afforded an oily substance (fract. II) (50 mg), IR $v_{\max }^{\mathrm{CHCl}_{3}} \mathrm{~cm}^{-1}: 1733$. This substance was hydrolyzed by refluxing with $5 \% \mathrm{KOH}-$ methanol $(6 \mathrm{ml})$ for $4 \mathrm{hr}$, and worked up in the usual way to yield an oily acidic substance $(15 \mathrm{mg})$, IR $\nu_{\max }^{\mathrm{CHCl}_{3}} \mathrm{~cm}^{-1}: 3600-2300,1703$. Methylation of the latter substance with $\mathrm{CH}_{2} \mathrm{~N}_{2}$ followed by silica gel column chromatography $(0.3 \mathrm{~g}, 0.5 \times 2 \mathrm{~cm})$ gave an oily ester mixture (methyl ester fraction (B)) $(12 \mathrm{mg}), \mathrm{IR} \nu_{\max }^{\mathrm{CHCl}_{8}} \mathrm{~cm}^{-1}: 1725$.

Separation of Fatty Acids from the Methanolic Extract_- To the methanolic extract was added purified water $(40 \mathrm{ml})$ and the solution was slowly distilled. The residue $(30 \mathrm{ml})$ was saturated with $\mathrm{NaCl}$ and extracted with ether (4 times). The ether extract was dried over anhyd. $\mathrm{MgSO}_{4}$ and the solvent was removed by evaporation to give a small amount of oily substance, which was chromatographed through a silica gel column $(2 \mathrm{~g}, 1 \times 5 \mathrm{~cm})$. Elution with pentane gave an ester mixture as an oil (fract. III). Subsequent elution with 1:9 ether-pentane gave a small amount of oily substance (fract. IV) having a valeric acid-like odor. Methylation of the latter with $\mathrm{CH}_{2} \mathrm{~N}_{2}$ afforded an oily ester mixture (methyl ester fraction (C)).

Gas Chromatography (GC)__ GC was carried out on a $10 \%$ PEG $20 \mathrm{M}$ column (stainless steel $2 \mathrm{~m} \times$ 3. mm i.d., on 60-80 mesh Chromosorb WNAW) at 50 , a $10 \%$ SE-30 column (stainless steel $1 \mathrm{~m} \times 3 \mathrm{~mm}$ i.d., on 60-80 mesh Chromosorb WNAW) at 50 , a 15\% Reoplex 400 column (stainless steel $2 \mathrm{~m} \times 3 \mathrm{~mm}$ i.d., on 60-80 mesh Chromosorb WNAW) at 50\%, and a 15\% PEGS column (stainless steel $2 \mathrm{~m} \times 3 \mathrm{~mm}$ i.d., on $60-80$ mesh Neopak 1A) at $150^{\circ}$ or $180^{\circ}$ with a Hitachi Gas Chromatograph Model 063 equipped with a hydrogen flame ionization detector. The carrier gas was nitrogen or helium ( $30 \mathrm{ml} / \mathrm{min})$.

GC-MS - A Hitachi Mass Spectrometer Model RMU-6 was combined with a Hitachi Gas Chromatograph Model K-53. GC was performed on a Golay column HB 2000 (stainless steel $45 \mathrm{~m} \times 0.5 \mathrm{~mm}$ i.d.,) at $30^{\circ}$, using helium $\left(0.6 \mathrm{~kg} / \mathrm{cm}^{2}\right)$ as the carrier gas. Mass spectra were measured under the following condition: ionizaticn voltage, $80 \mathrm{eV}$; accelerator voltage, $2 \mathrm{kV}$.

Acknowledgement This investigation was supported in part by a Grant-in-Aid for Scientific Research from Ministry of Education, which is gratefully acknowledged. Also we wish to express our deep gratitude to Dr. Y. Naya of Institute of Food Chemistry for measurement of GC-MS of the odorous metabolites of Synedra rumpens KüTz, and to Professor Y. Inubushi of this Faculty for his hearty encouragement throughout this work. 